\title{
An efficient low-cost laboratory workflow for the study of blood cells and RNA extractions in marine invertebrates
}

\author{
Stefania Gutierrez $z^{1,2^{*}}$ \\ ${ }^{1}$ Instituto de Biociências, Depto de Zoologia, Universidade de São Paulo, USP. ${ }^{2}$ Calima \\ Foundation, www.fundacioncalima.org. \\ *Correspondence to: astefania.gutierrez@gmail.com \\ ORCID: https://orcid.org/0000-0002-6560-7706
}

\section{Abstract}

Marine invertebrates are model organisms in several areas of biological sciences, being a source of massive biological information. Although, the scientific relevance of marine invertebrates, the research with them can be limited for their tissue characteristics and troubles for the replication of physical and chemical properties of seawater. Thence, the main goal of this laboratory workflow is to provide a useful methodological approach to reduce the experimental limitations during the study of marine invertebrates. The present study describes experimental methodologies for the collection, transport, and maintenance of sessile tunicates. Also, an approach to observe and characterize, a diverse population of blood cells in marine invertebrates, by several cytological stains and electron microscopy. Lastly, suggestions and protocols to extract quality RNA from samples with high concentrations of salts, pigments, secondary metabolites, and polysaccharides. This methodological approach can be easily adapted to other marine invertebrates, moreover uses low-cost reagents and 
widely available laboratory equipment. Making possible the study of different types of marine animals in diverse locations.

Keywords: Marine invertebrates, RNA extraction by LiCl precipitation, electron microscopy of blood cells, cytology stains, tunicate culture.

\section{Introduction}

The ocean is $70 \%$ of our planet's surface. Life originated and diversified in the oceans, and a large proportion of biodiversity is concentrated in oceanic environments (Barnes \& Hughes, 1982; Kaiser et al., 2010). A relevant proportion of marine biodiversity and biomass is conformed by marine invertebrates. These animals are also preponderant in marine ecosystems, being keystone species in some cases, such as the coral reefs (Barnes \& Hughes, 1982). Accordingly, it is possible to obtain massive biological information by the study of marine invertebrates.

Marine invertebrates have been the model for biological research for centuries, being a source of massive biological information. Cephalochordates and hemichordates have been studied regarding their evolutionary aspects (Swalla \& Smith, 2008). Sea urchins, tunicates, mollusks, and polychaetes, are model organisms to study gametogenesis, embryogenesis, cell signaling, and developmental processes (Gilbert, 2003). Cephalopods have been studied for innovations in nanomaterials (Phan et al., 2013). Sea urchin and tunicate embryos are used to understand the toxicity of chemical compounds in marine environments (Bellas et al., 2005). Molluks and crustaceans are biondicators for the study of plastic pollution in the marine food webs (Setälä et al., 2018). The marine invertebrates are a crucial source of biological knowledge. Although, the 
relevance of marine invertebrates in biological science, the research with them is limited for their tissue characteristics and troubles during replication of marine environment.

The research with marine invertebrates required specific conditions (e.g. salinity, $\mathrm{pH}$, and temperature), related to the type of organism, or the kind of methodological procedure. Some marine ecosystems are hard-to-reach places, making difficult and expensive the transport of the specimens and samples (Calado \& Leal, 2015). In vivo experiments required, the maintenance of animal culture, and cell cultures. The replication of marine conditions in the laboratory can be challenging, restricting the type of in vivo experiments (Calado \& Leal, 2015; Cima, 2010). The higher concentration of salts and secondary metabolites frequently founded in the marine invertebrates can be another limiting aspect in the study of these animals. As well as, the hard external tissues of some organisms (e.g. calcareous skeletons, tunics of polysaccharides) (Cima, 2010; Dixon et al., 2002). These restrictions typical of marine animals reduce the quantity and quality of samples, affecting the experimental procedures (Dixon et al., 2002).

Thus, the main goal of this laboratory workflow is to provide a useful and efficient experimental approach, to solve troubles during the extraction and manipulation of blood cells, and RNA extractions in marine invertebrates. Also, taking into count the use of simple and low-cost reagents and equipment.

\section{Methodologies}

These procedures were developed and standardized during the study of the colonial tunicates Symplema brakenhielmi and S.rubra. These marine invertebrates have a dense and elastic tunic composed of cellulose. The small zooids are inside this hardly breakable tunic. Moreover, the internal tissues are surrounded by blood with a high concentration of pigments and secondary metabolites. These characteristics of Symplegma species restrict the quantity and quality of tissues, 
available for nucleic acid extractions, cytological techniques, and electron microscopy. The resultant protocols were successfully tested in other tunicates such as Botryllus sp., Styela plicata, and the cnidarian Cassiopea sp.

\subsection{Taxon sampling}

Symplema brakenhielmi and S.rubra are benthic animals, living attached to hard marine substrates. Rocky shores, mangroves, and Yacht port are locations with abundant colonial tunicates. Yacht ports are ideal places to collect because these locations provide colonial animals in abundance and ease of collection. Colonial tunicates are usually located in floating buoys, cords, and pilots (Fig.1 Process 1). Pieces of colonies between $1-2 \mathrm{~cm}^{2}$ are carefully removed from the substrate, cleaned, and placed in recipients with fresh seawater. Colony pieces are attached to microscope glass slides with a thread and stored in microscope slide boxes with perforations for water circulation. Boxes are attached to floating structures in Yacht port for three weeks. The attached colonies are cleaned, to be subsequently used in experiments (Fig.2 A, B).

\subsection{Sample transporting and culture}

Transportation of alive colonies requires a thermal container with an oxygen source. Alive colonies need time to adapt from ocean conditions to culture system tanks. For the first twelve hours after transportation, new colonies need to be maintained with $50 \%$ of original seawater and system seawater, without food. A feeding regime with living phytoplankton is useful to maintain healthy colonies (Fig. 2 C-D). The mixture of Isochrysis, Thalassiosira, Pavlona, Nanochlorpsis has nutrients for growing colonies (Fig.1 Process 2). 
Samples for nucleic extraction need to be cleaned to remove other organisms. This activity is more efficient with the aid of a stereo-microscope. Specimens must be kept without food in filtered seawater (FSW) overnight before tissue extraction. Samples collected in remote areas can be cleaned as best as possible and stored in ethanol $70 \%$ for DNA extraction, or RNAlater for RNA extraction. The immersion of tissues in the preserving solution is a key step to guarantee tissue preservation and successfully nucleic acid extractions. Thus, in the cases of animals with hard external tissues (e.g hard tunics ), is necessary to make orifices to the external part or dissect internal organs, to put them in contact with the preserving solution (Fig.1 Process 3B).

\subsection{Blood cells characterization}

Blood cells in Symplegma colonies are diverse, consisting of eleven types of cells. These blood cell populations have different sizes, cellular content (e.g. vesicles, vacuoles, dense granules), and cytoplasmic characteristics (e.g. amoeboid cytoplasm and pseudopodia) (Gutierrez \& Brown, 2017). Because blood cells present such diverse characteristics, different cells are observable with different stains and fixing methodologies. Therefore it is necessary to use diverse methodologies, to encompass the greatest possible number of blood cell types (Fig.1 Process 3A).

One of the first approaches to observe and characterize blood cells is by cellular morphology (Ballarin \& Cima, 2005; Cima, 2010; Cima et al., 2001). The cytology stains are made in histological sections and extracted blood cells. Histological sections are useful to identify internal the morphology of zooids and buds, as well as the location of blood cell types within the colonies. However, amoeboid blood cells and cells with large vacuoles are excluded for the abrasive steps (e.g. xylol and ethanol series of dehydration) in histological procedures. Cytology stains in extracted blood cells are useful to in vivo studies, and to observe the diversity of blood cell populations. 


\subsubsection{Histology in Symplegma colonies}

Tunicate colonies attached to slides must be cleaned with a soft brush and let without food overnight in filtered seawater (FSW). Tissues colonies are relaxed in FSW with menthol crystals covering the water surface for 15 minutes, to be fixed with $4 \%$ paraformaldehyde (diluted in FSW), at $4{ }^{\circ} \mathrm{C}$ overnight. After fixation colonies are washed three times for 15 minutes with PBS and distilled water. Tissues are dehydrated by ethanol series $(25 \%, 50 \%, 70 \%, 80 \%, 90 \%, 100 \%)$ and two xylol washes for 30 minutes. Tissues are embedded in paraffin to cut in sections (6 um). Sections are re-hydrated by xylol washes for 10 minutes and ethanol series $(100 \%, 95 \%, 90 \%, 80 \%$ 70\%). Finally, sections are stained with hematoxylin and eosin and mounted with Entellan.

\subsubsection{Blood cell extraction}

Blood cell extraction follows a previously described protocol (Cima, 2010), with some changes to improved obtained results. The main limitation to work with blood cells is the constant coagulation and the preservation of blood cell integrity. The constant use of anticoagulants during all the blood extraction is useful to reduce blood clots. Blood cell integrity is preserved by, maintaining the sample in ice, and preparing reagents in FSW for cellular osmoregulation.

Clean attached colonies are immersed in anticoagulant solution (10 mM L-cysteine and 0,38 $\%$ sodium citrate, diluted in FSW) for 5 minutes, then the colony is dried with a soft paper towel. The blood vessels edgs (i.e. Ampullae) are gently cut, the blood is collected with a micropipette, which is rinsed constantly with anticoagulant (Fig. 3A). Following the blood collection, the anticoagulant is washed by centrifuging for 15 minutes at $3000 \mathrm{rpm}$. Hemocytes are re-suspend in $500 \mu \mathrm{l}$ of a solution with 1/3 Anticoagulant and 2/3 FSW. This solution prevents posterior coagulation, and maintain the integrity of the cells. The blood cell solution is mixed gently with a micropipette. Drops from this blood solution are left in slides coated with Poly-L Lysine to attach 
the blood cells. Slides are maintained in a humid chamber to prevent cell desiccation. After blood cells attachment, liquid excess is discarded placing the slides vertically (Fig. 3B).

\subsubsection{Cytological stains}

The cytological stains are used to observe the cellular size, content, and conspicuous organelles such as vacuoles, vesicles, and pseudopodia. The general cellular morphology characteristics (i.e. nucleus size, nucleus-cytoplasm ratio, acid and basic contents) are described with hematoxylin and eosin stain. Blood cell populations are characterized with Giemsa stain, used for blood cytology. The lipid content is described with Sudan Black stain. These stains can be abrasive for big vacuolated cells and cells with pseudopodia, and change the cellular morphology. Thence, the Neutral Red (vital stain) is used to observe living cellular morphology and cellular behaviors.

\section{$\underline{\text { Hematoxylin and eosin stain }}$}

Blood cells attached to slides are fixed for 15 minutes, with 4\% Paraformaldehyde (diluted in FSW). Fixed cells are washed with PBS, and stained with Meyer hematoxylin for 10 minutes and eosin for 5 minutes. Blood cells are mounted using glycerin and sealed with a coverslip.

\section{$\underline{\text { Giemsa stain }}$}

Blood cells attached to slides are fixed for 30 minutes at $4{ }^{\circ} \mathrm{C}$, with the solution $1 \mathrm{~g} \mathrm{NaCl}$ and $1 \mathrm{~g}$ sucrose in $1 \%$ glutaraldehyde in FSW. Fixed cells are washed with PBS, and stained with 10\% Giemsa for 5 minutes. Blood cells are mounted using glycerin and sealed with a coverslip. 
Neutral red solution ( $8 \mathrm{~m} / \mathrm{L}$ in FSW) is added to the attached blood cells. Living hemocytes are observed directly with a coverslip.

\section{$\underline{\text { Sudan Black for stain lipids }}$}

Blood cells attached are washed with PBS, and with $70 \%$ ethanol. Cells are stained with a saturated solution of Sudan Black in $70 \%$ ethanol for $15 \mathrm{~min}$ at $70^{\circ} \mathrm{C}$. The stain is washed with $70 \%$ ethanol and distilled water. Cells are mounted using glycerin.

\subsubsection{Transmission electron microscopy}

Transmission electron microscopy (TEM) is a useful technique to observe in detail cellular morphology and cellular organelles. Thus, TEM is a necessary technique for the identification and description of blood cell populations (Cima, 2010; Hirose et al., 2003). Maintain cellular morphology integrity is a vital step for TEM quality in colonial tunicates. Blood cell populations interacted differentially with the several fixatives. Therefore the use of diverse fixatives procedures is essential to observe the blood cell diversity.

The fixative solution used previously by Cima (2010), (1.5\% glutaraldehyde in $0.2 \mathrm{M}$ cacodylate buffer, $1 \%$ saccharose, $1.7 \mathrm{NaCl} \%$ adjust at $\mathrm{pH}=7.4$ ) is useful for smaller cells, precursors cells, and cells with homogeneous vesicles. The Karnovsky (1965) modified solution for marine organisms (1.5\% glutaraldehyde, $1.2 \%$ paraformaldehyde in $0.2 \mathrm{M}$ cacodylate buffer, $1.5 \%$ $\mathrm{NaCl}, 1 \%$ saccharose, adjust at $\mathrm{pH}=7.4$ ) is useful for large vacuolated cells, and amoeboid cells.

Thence, for electron microscopy, both fixatives are used to have good coverage of the different types of cells. One quantity of the samples is processed with the Cima, 2010 fixative, and another quantity is processed with Karnovsky (1965) modified for marine organisms. For fixation, 
clean attached colonies are immersed in fixative solution for 1 hour at $4^{\circ} \mathrm{C}$. Then pieces of blood vessels are dissected and fixed for 3 hours at $4^{\circ} \mathrm{C}$. This step improves fixative penetration, limited by the cellulose tunic. Tissues pieces are postfixed with $1 \% \mathrm{OsO}_{4}$ in $0.2 \mathrm{M}$ cacodylate buffer for 1 hour. Samples are dehydrated in ethanol series, embedded in Spurr's resin, and polymerized at $58^{\circ} \mathrm{C}$. Tissues are sectioned and collected on copper grids. Sections are contrasted with lead citrate and observed in a Zeiss EM 900 Transmission Electronic Microscope operated at 80kV.

\subsection{RNA extractions}

DNA and RNA extraction is an essential methodology in biological studies. The biological information from RNA has (DNA transcription and expression) diverse applications in biological research, such as transcriptome studies, in situ hybridization, and quantitative RNA expression (Mehra, 1996).

A critical aspect during the experimental procedures with RNA is the maintenance of RNA integrity. The preservation of the RNA starts with good quality samples, reducing the quantity of RNAases (enzymes that digest RNA), and cold temperatures. In tunicates, the elevated salt concentration and the hard tunic composes of cellulose, are the main restrictions during RNA extraction procedures. The steps to reduce these restrictions are (i) wash the sample with ice-cold PBS before the extraction to reduce the excess salt; (ii) the addition of sodium compounds to the isopropanol step to improve RNA precipitation (Tri-Reagent modified protocol Sambrook \& Russell, 2001); (iii) the dissection of muscular tissue in solitary tunicates, and colonies with large zooid, to avoid the cellulose tunic in the RNA extraction. The dissection in colonies with small zooids requires the extraction of a considerable number of zooids to obtain enough material for the extraction. However, there are colonies (e.g Symplegma brakenhielmi and S.rubra) with a strongelastic tunic hard to break during the extraction, with a higher concentration of pigments and 
alkaloids compounds (Youssef et al., 2015) (Fig. 4A). In which the dissections and the previous recommendations are insufficient to prevent the quick degradation of RNA. In the case of $S$. brakenhielmi and S.rubra the unique protocol that worked for RNA extraction, after test several protocols and kits for RNA extraction (Fig. 4B), is the present protocol with lithium chloride used generally for plants (Barlow \& Gammack, 1963). Thus, this methodological approach can be an appropriate procedure for the RNA extraction in marine invertebrates with similar characteristics.

\subsubsection{Tri-Reagent modified protocol}

The Tri-Reagent protocol follows a previously described protocol (Sambrook \& Russell, 2001). Fresh tissues, samples stored in RNA later and frozen in liquid nitrogen, are used for RNA extraction with satisfactory results. Samples are washed with ice-cold 1X PBS. Tissue homogenization is with liquid nitrogen and a ceramic mortar, or with a plastic homogenizer with TRIzol solution. After homogenization, the solution is live for 5 minutes at room temperature, posterior steps are at $4^{\circ} \mathrm{C}$. The homogenate is centrifuge by $12,000 \mathrm{rpm}$ for 10 minutes, to remove the insoluble material (extracellular membranes, polysaccharides). The supernatant is transferred into a new tube, for organic separation with chloroform. Supernatant and chloroform are mixed with a vortex shaker and stand for 5 minutes, then centrifuge at 12,000 rpm for 15 minutes. The organic separation is repeated, to reduce salt and proteins excess, and polysaccharide residues from the tunic. RNA is with isopropanol and an RNA precipitation solution $(1.2 \mathrm{M} \mathrm{NaCl}$ and $0.8 \mathrm{M}$ disodium citrate), for 10 minutes. Liquid excess is removed after 10 minutes of centrifugation at 12,000 rpm. Pellet is dried by air-drying for 5 minutes and washed with $75 \%$ ethanol. Ethanol is removed by 5 minutes of centrifugation at $12,000 \mathrm{rpm}$ and evaporation of residues. The clean pellet is diluted in free RNAse water and storage at $-80^{\circ} \mathrm{C}$. 


\subsubsection{RNA extraction using $\mathrm{LiCl}$ for precipitation}

This protocol has steps to extract precisely the RNA from samples with polysaccharides preventing RNA degradation. Before the extraction, samples are frozen with liquid nitrogen and macerated with a Tissue Lyzer machine (40 seconds, 30 revolutions per second. The buffer extraction contains SDS detergent to permeate cellular membranes and solubilize proteins. There are washes with $\mathrm{LiCl}$ to select and precipitate the RNA preventing polysaccharides precipitation. Moreover, there are washes with sodium acetate to remove the residual polysaccharides from the RNA pellet (Barlow \& Gammack, 1963).

RNA protocol using $\mathrm{LiCl}$ was followed as recommended (Barlow \& Gammack, 1963). Frozen powder is immersed and mixed in a solution $50 \%$ of extraction buffer $(0,2 \mathrm{M}$ Tris- $\mathrm{HCl} \mathrm{pH}$ 7.5, 0,1 M LiCl, 5mM EDTA, 1/10 of the total volume of SDS 10\%), $50 \%$ of phenol:chloroform (1:1). Homogenate is centrifuge at $14000 \mathrm{rpm}$ for 5 minutes at $4^{\circ} \mathrm{C}$. A solution of $6 \mathrm{M} \mathrm{LiCl}$ is added to the supernatant, the mixture is stored with ice at $-20^{\circ} \mathrm{C}$ overnight. $\mathrm{LiCl}$ is washed by centrifugation at $14000 \mathrm{rpm}$ for 10 minutes at $4^{\circ} \mathrm{C}$. Pellet is washed with $3 \mathrm{M} \mathrm{LiCl}$ by 30 minutes of vortex shaking, and centrifugation. Pellet is resuspended with free RNAse water and centrifugate for 1 minute, to remove the insoluble material (extracellular membranes, polysaccharides). The supernatant is mixed with solution of $1 / 3$ of sodium acetate and $2 / 3$ of $100 \%$ ethanol. After a manually homogenization solution is stored at $-80^{\circ} \mathrm{C}$ for 15 minutes. Sodium acetate is washed with centrifugation for 15 minutes. Pellet is washed with $70 \%$ ethanol, then centrifugate for 5 minutes. Pellet is resuspended in free RNAse water and incubate for 15 minutes at $55^{\circ} \mathrm{C}$, to dilute the RNA precipitate, then stored at $-80^{\circ} \mathrm{C}$ (Fig. $4 \mathrm{C}$ ). 


\section{Conclusions}

The methodological approach used for blood characterization was efficient to observe different types of blood cells (e.g hyaline amebocytes, vacuolated cells, granular cells, precursorlike cells). In the case of Symplegma brakenhielmi and S. rubra, was possible to identify and describe about eleven types of blood cells. Therefore, the proposed workflow increases the capacity to detect diverse blood cell populations, allowing a better understanding of blood cells and hematopoiesis in marine invertebrates.

The two methods of RNA extractions are useful to obtain high-quality RNA. The modified method of Trizol is faster and required simple reagents and equipment. The modifications in the organic separation and precipitation of RNA improves the obtained results, being this method a good option to extract RNA in marine organisms.

The method of extraction with lithium is useful to extract RNA from samples with pigments, secondary metabolites, and polysaccharides. This method takes two days for the overnight precipitation with LiCL, however, the results are very satisfactory, allowing high-quality RNA extraction from difficult samples.

The proposed workflow is efficient for the transportation, nucleic acid extractions, and blood cell studies with tunicates. Also, the presented protocols can be easily adapted to other marine invertebrates. This methodological approach uses low-cost reagents and widely available laboratory equipment. Making possible the study of marine invertebrates in diverse locations.

Acknowledgments: This research was supported by CAPES Brazilian agency, and the grant 2015/22650-2 from São Paulo Research Foundation (FAPESP). I would like to thank T. Silveira and Professor M.A. Van Sluys (GateLab, IB-USP) for their support with the adaptation of RNA 
extraction protocol using $\mathrm{LiCl}$, from plants to marine invertebrates. Many thanks to Professor D.

Lahr (LEP, IB-USP) for his advice on scientific writing.

\section{References}

Ballarin, L., \& Cima, F. (2005). Cytochemical properties of Botryllus schlosseri haemocytes: indications for morpho-functional characterisation. 2009 (Vol. 49). Retrieved from http://ejh.pagepress.org/index.php/ejh/article/view/952

Barlow, J., \& Gammack, D. (1963). A simple method for the quantitative isolation of undegraded high molecular weight ribonucleic acid. Biochemical and Biophysical Research Communications, 13(1), 61-66.

Barnes, R. S. K., \& Hughes, R. N. (1982). An Introduction to Marine Ecology. An Introduction to Marine Ecology. https://doi.org/10.1002/9781444313284

Bellas, J., Beiras, R., Mariño-Balsa, J. C., \& Fernández, N. (2005). Toxicity of Organic Compounds to Marine Invertebrate Embryos and Larvae: A Comparison Between the Sea Urchin Embryogenesis Bioassay and Alternative Test Species. Ecotoxicology, 14(3), 337. https://doi.org/10.1007/s10646-004-6370-y

Calado, R., \& Leal, M. C. (2015). Chapter One - Trophic Ecology of Benthic Marine Invertebrates with Bi-Phasic Life Cycles: What Are We Still Missing? In B. E. B. T.-A. in M. B. Curry (Ed.) (Vol. 71, pp. 1-70). Academic Press. https://doi.org/https://doi.org/10.1016/bs.amb.2015.07.001

Cima, F. (2010). Microscopy methods for morpho-functional characterisation of marine invertebrate haemocytes. Microscopy: Science, Technology, Applications and Education, 1100-1107. Retrieved from http://www.formatex.info/microscopy4/1100-1107.pdf

Cima, F., Perin, A., Burighel, P., \& Ballarin, L. (2001). Morpho-functional characterization of haemocytes of the compound ascidian Botrylloides leachi (Tunicata, Ascidiacea). Acta Zoologica, 82(4), 261-274. https://doi.org/10.1046/j.1463-6395.2001.00087.x

Dixon, D. R., Pruski, A. M., Dixon, L. R. J., \& Jha, A. N. (2002). Marine invertebrate ecogenotoxicology: a methodological overview. Mutagenesis, 17(6), 495-507. https://doi.org/10.1093/mutage/17.6.495

Gilbert, S. (2003). Developmental Biology (Seventh Ed). Sunderland, MA: Sinauer Associates, Inc.

Gutierrez, S., \& Brown, F. D. (2017). Vascular budding in Symplegma brakenhielmi and the evolution of coloniality in styelid ascidians. Developmental Biology, 423(2). https://doi.org/10.1016/j.ydbio.2017.01.012 
Hirose, E., Shirae, M., \& Saito, Y. (2003). Ultrastructures and Classification of Circulating Hemocytes in 9 Botryllid Ascidians (Chordata: Ascidiacea). Zoolog Sci, 20(5), 647-656. https://doi.org/10.2108/zsj.20.647

Kaiser, Michael, J., Attrill, M., \& Jennings, S. (2010). Marine Ecology. Process, Systems, and Impacts. Fish and Fisheries. https://doi.org/10.1111/j.1467-2979.2006.00221.x

Karnovsky, M. J. (1965). A Formaldehyde-Glutaraldehyde Fixative of High Osmolality for Use in Electron Microscopy. The American Society for Cell Biology Source: The Journal of Cell Biology, 27(2), 1-149.

Mehra, M. (1996). RNA Isolation from cells and tissues. In P. Krieg (Ed.), A laboratory Guide to RNA: Isolation, Analysis, and Synthesis (p. 41). New York: Wiley-Liss.

Phan, L., Walkup IV, W. G., Ordinario, D. D., Karshalev, E., Jocson, J.-M., Burke, A. M., \& Gorodetsky, A. A. (2013). Reconfigurable Infrared Camouflage Coatings from a Cephalopod Protein. Advanced Materials, 25(39), 5621-5625. https://doi.org/doi:10.1002/adma.201301472

Sambrook, J., \& Russell, D. (2001). Molecular Cloning a Laboratory Manual (Third edit). New York: Cold Spring Harbor Laboratory Press.

Setälä, O., Lehtiniemi, M., Coppock, R., \& Cole, M. (2018). Microplastics in marine food webs. Microplastic Contamination in Aquatic Environments: An Emerging Matter of Environmental Urgency. https://doi.org/10.1016/B978-0-12-813747-5.00011-4

Swalla, B. J., \& Smith, A. B. (2008). Deciphering deuterostome phylogeny: Molecular, morphological and palaeontological perspectives. Philosophical Transactions of the Royal Society B: Biological Sciences, 363(1496), 1557-1568. https://doi.org/10.1098/rstb.2007.2246

Youssef, D. T. A., Mohamed, G. A., Shaala, L. A., Badr, J. M., Bamanie, F. H., \& Ibrahim, S. R. M. (2015). New purine alkaloids from the Red Sea marine tunicate Symplegma rubra.

Phytochemistry Letters, 13, 212-217. https://doi.org/10.1016/j.phytol.2015.06.012 


\section{Figures}

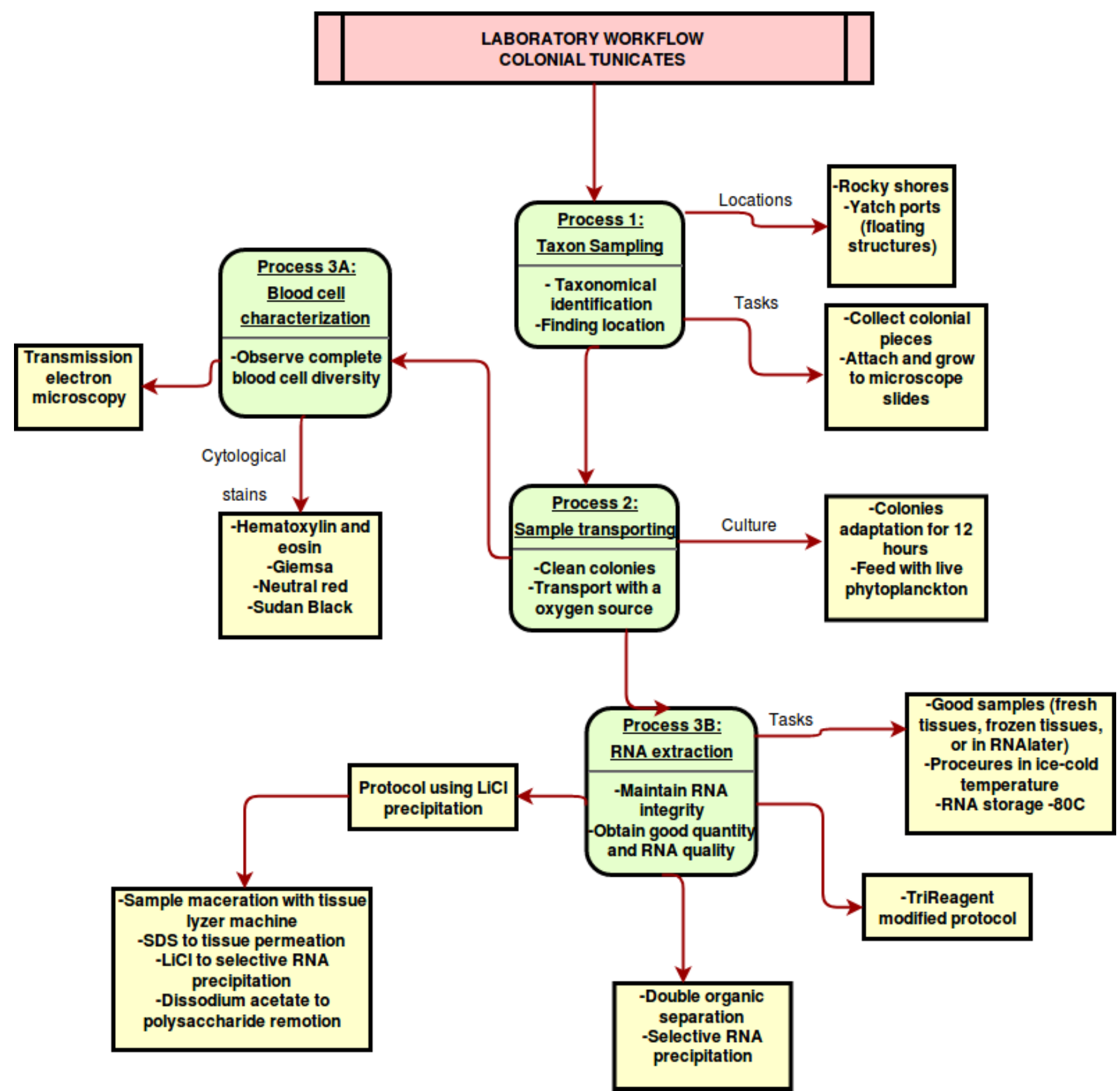

Figure. 1 Summary of the methodological workflow. The workflow is composed by taxon

sampling (process 1), sample transporting (process 2), blood cell characterization (process $3 \mathrm{~A}$ ) and RNA extraction (process 3B). 

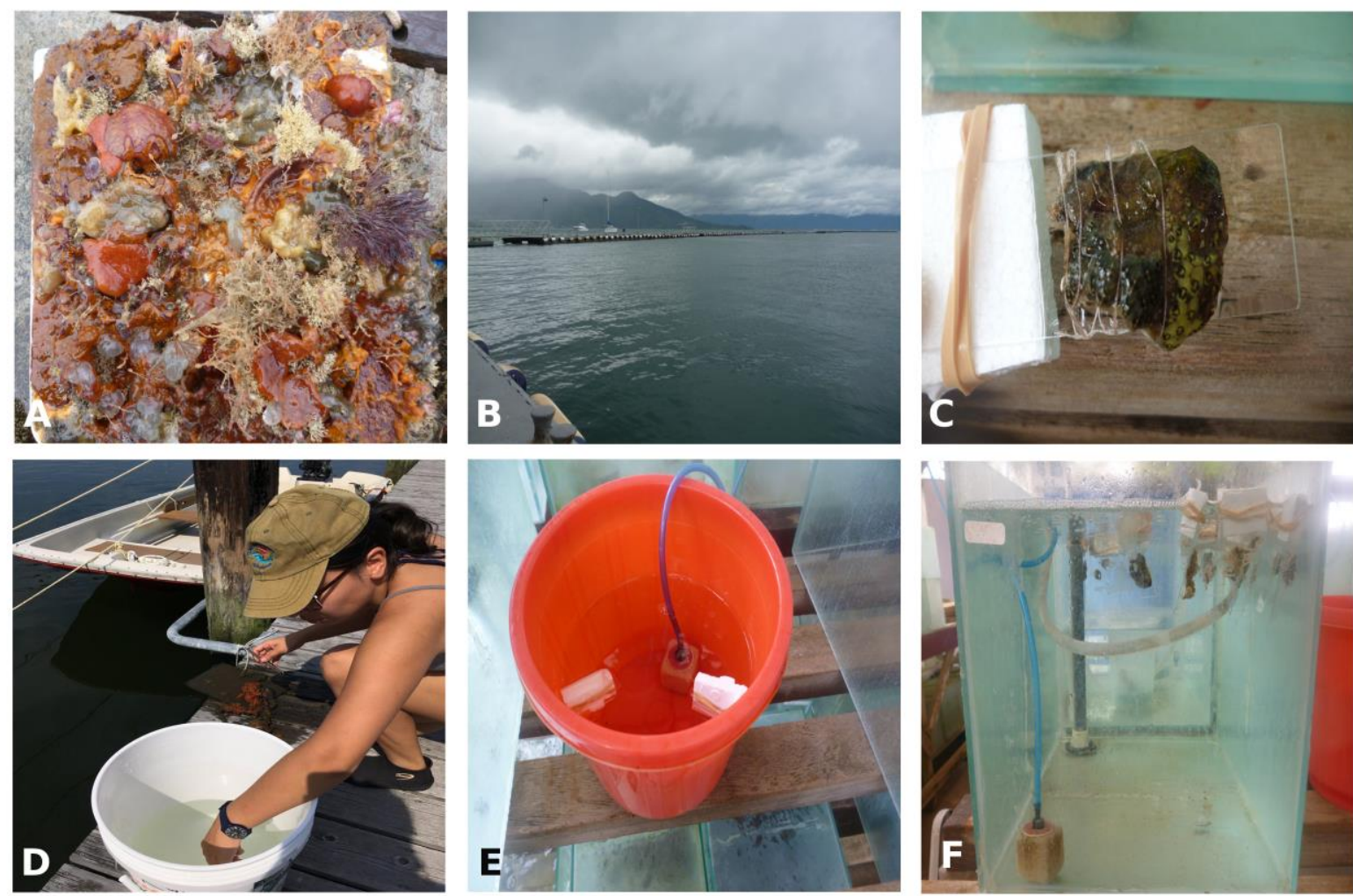

Figure. 2 Taxon sampling and sample transporting. (A) Benthic community in a buoyant structure, morphological characters (e.g. color, individual size, tunic texture and color) are used for taxonomic identification. (B) Floating yacht port structures, are useful to collect and grow attached tunicates. (C) Symplegma brakenhielmi colony, attached to a microscope slide with thread. (D) Pieces of collected colonies are maintained in recipients with fresh water, these pieces are attached to slides or transported to the laboratory (Picture by Shane Jinson, Embryo-course 2018 MBL). (E) Recipients for samples transportation have an air source, to maintain oxygen levels during transportation. (F) Attached colonies are maintained in culture systems with seawater and oxygenation. Colonies need to float or stay at higher level of aquarium bottom, to improve filtering and to prevent organic material contamination. 

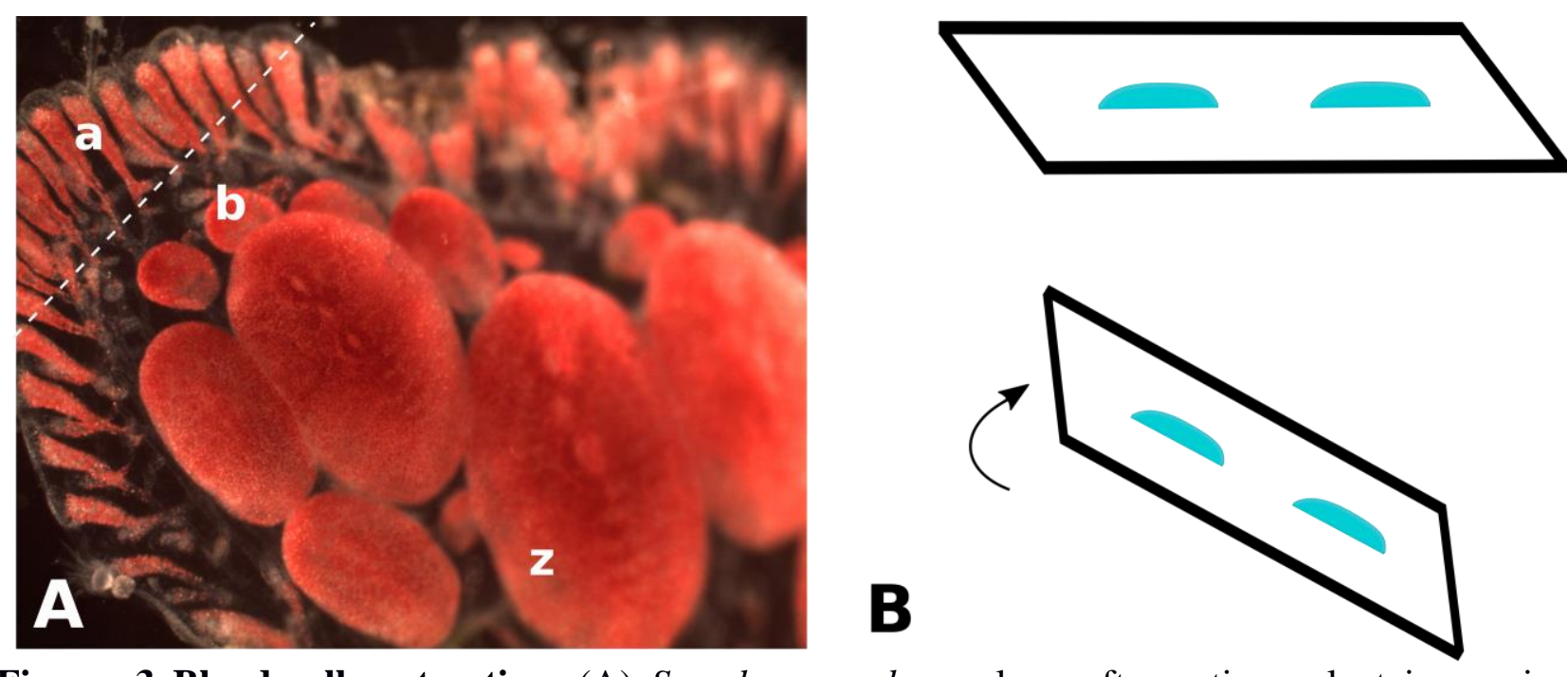

Figure. 3 Blood cells extraction. (A) Symplegma rubra colony after anticoagulant immersion, ampullae are cutting for extract the blood. (B) Blood cell solution is dropped in a slide, for cell adhesion, then slide is placing vertically to remove liquid excess.
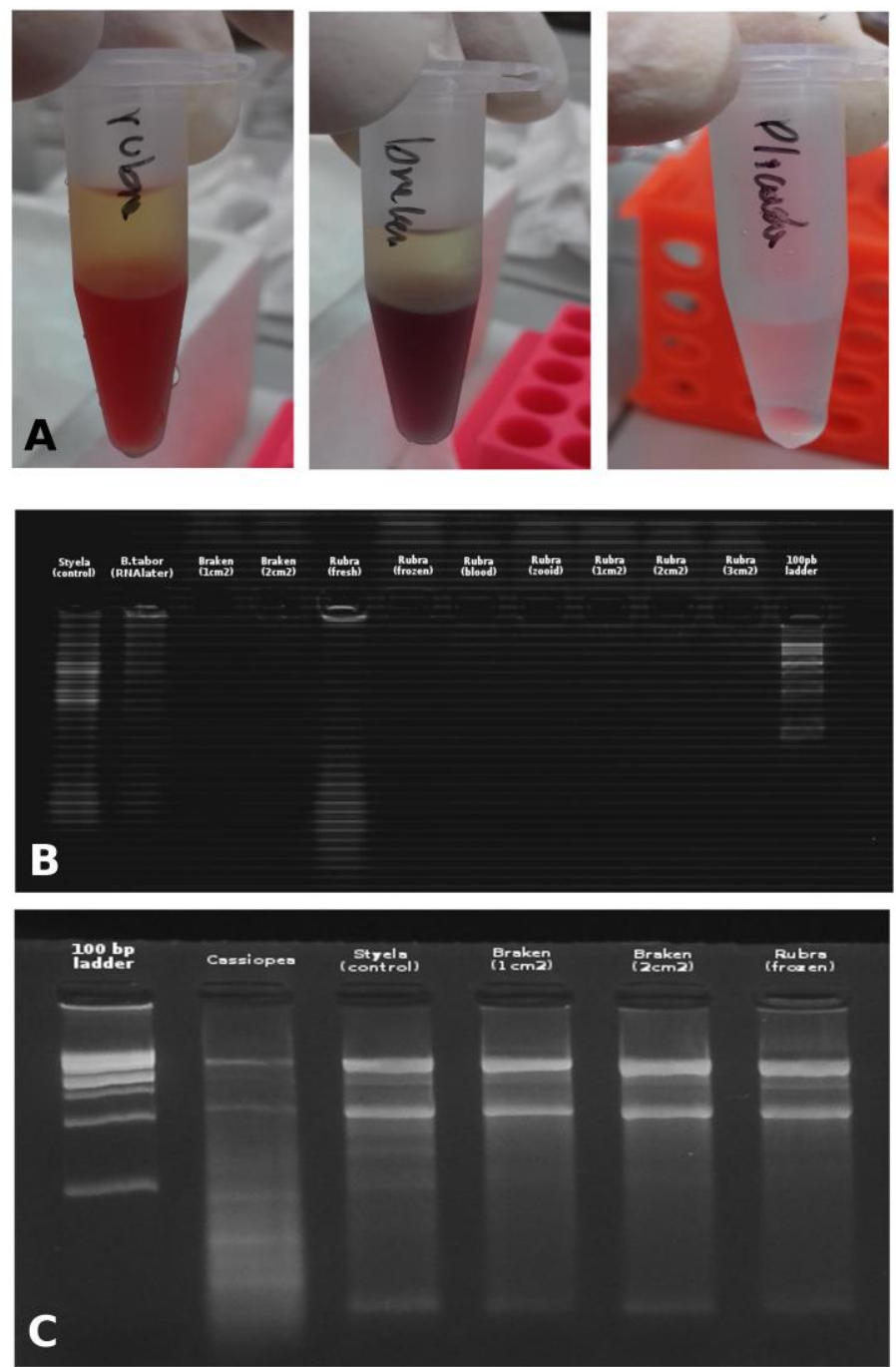
Figure. 4 RNA extraction. (A) Symplegma rubra and S. brakenhielmi samples contain pigments which are extracted with the RNA, even in the organic separation. Whereas, Styela plicata (control) sample is colorless. (B) RNA extraction using the tri-Reagent modified protocol is useful to extract high-quality RNA from tunicate samples (Styela plicata), and small tissue samples (Botryllus tabori). However Tri-Reagent modified protocol is useless to extract RNA from Symplegma samples (frozen tissue, blood cells, dissected zooids, colonies of different sizes) or high-quality RNA (alive S.rubra colony). (C) RNA extraction using $\mathrm{LiCl}$ for precipitation is useful to extract high-quality RNA from S.rubra and S. brakenhielmi samples from frozen and fresh material, as well from Styela plicata and cnidarians such as Cassiopea sp.

\section{Supplementary materials}

\subsection{Process 1: Taxon sampling}

-Using knifes and spatulas collect the tunicates carefully to do not damage the organisms.

-Transport the samples in sea water to laboratory. The samples are classified by morphological characteristics, like color, form and shape. Each sample is labeled with a number and collect place.

-In colonial specimens sample is dividing for different analysis, in solitary specimens, more than one individual is collected. One sample fragment (or individual) is storage in $70 \%$ Ethanol to molecular analysis, other part of tissue is fix in $4 \%$ formaldehyde to morphological observations. The remaining tissue is using to settle in glass slides. For RNA analysis samples can be preserve in RNAlater, frozen in liquid nitrogen and storage at $-80^{\circ} \mathrm{C}$.

\subsection{Process 2: Transporting and maintenance of living tunicates 6.2.1 Settled colonial tunicates}

-Colonies are attached with thread on $5 \mathrm{~cm}$ X $7.5 \mathrm{~cm}$ glass slides.

-During attachment process microscope slides are maintained in slide boxes with apertures to permit water circulation. Usually this process occurs in one or two weeks in the ocean (attach boxes to port structures) or two and three weeks in a culture system.

-When tunicate is attached to slide, the thread is remove with tweezers. It is important that the attached tunicates are floating or in a surface superior to tank bottom. This allows filtration and prevent contamination with organic wastes. Every day tunicates are feeding with living phytoplankton. The food mixture is prepare from $1 / 4$ of each living algae (Isochrysis, Thalassiosira, Pavlona and Nanochlorpsis), in a approximated concentration of 170,000 cell $/ \mathrm{ml}$.

\subsubsection{Precautions with culture system:}

\section{A. Ammonium and organic wastes:}

One of the crucial aspect in recirculating systems is the accumulation of ammonium and other toxic compounds for animals. The first way to reduce the quantity of these compounds is to prevent the accumulation of organic material pieces. The rest of food and feces begin a process of decomposition affecting the quality of the water. The biofilter is the principal way to reduce the 
accumulation of ammonium, because the microorganisms in the biofilter processing the ammonium in a sequence of chemical reactions that decompose the ammonium in non toxic forms (Losordo et al.,1998; Wright, 2011) ${ }^{1}$ :

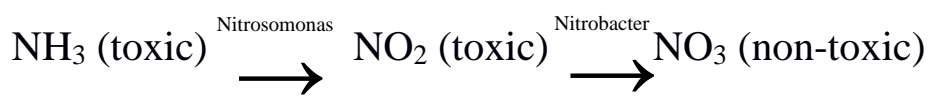

Consequently is necessary maintain the biofilter in good conditions controlling the variables of the system ( $\mathrm{pH}$, salinity and temperature). Also add probiotics to the biofilter to maintain system stability(Marion et al., 2011; Wright, 2011).

\section{B. Oxygen levels}

The levels of oxygen are usually a problem in recirculating systems, because the water is maintain in the system for a long period and it is necessary provide oxygen to the system. Also the process to reduce the ammonium in the biofilter consume oxygen, reducing the levels of oxygen in the system. Thus oxygen sources are critical to maintain healthy conditions to the animals. Specially in systems with a high density of animals, or with animals that require large food quantity and produce more organic wastes (e.g solitary tunicates) (Grøttum et al.,1997).

\section{Rotten eggs smell $=>$ hydrogen sulfide presence}

Rotten eggs smell in the seawater is a indicator of hydrogen sulfide presence. This compound is produced by anoxic bacterias, for the increment of organic decomposition. Resulting in anoxic areas in the culture system, usually in are with less water movement and less oxygen. A constant water movement and pipe cleaning, are strategies to control the increment of hydrogen sulfide (Grøttum et al., 1997; Losordo et al., 1998).

\subsection{Process 3A: Blood cell characterization}

\subsubsection{Blood cell extraction follows a previously described protocol (Cima, 2010), with some changes to improved obtained results \\ -Anticoagulant solution:}

$-10 \mathrm{mM}$ L-cysteine (which binds the thiols of plasma proteins )

$-0.38 \%$ sodium citrate (a calcium chelating agent)

-The solution is in filtered and sterilized sea water adjusted at $\mathrm{pH}$ 7.5.

* Note that, before blood collection, glass micropipette must be repeatedly rinsed with the anticoagulant solution, in order to prevent hemocytes from adhering to its glass walls.

\section{-Hemocyte collection solitary ascidians:}

-The haemolymph containing hemocytes can be obtained by cutting the tunic and puncturing the heart.

\section{-Hemocyte collection colonial ascidians:}

1. Put the colony by 5 minutes at r.t in $10 \mathrm{~cm}$ petri dish containing $50 \mathrm{ml}$ of an anticoagulant solution. 
2. Dry the colony.

3. Cut gently some ampullae.

4. Collect the blood with a micropipette (If is necessary put anticoagulant on the slide to collect the blood).

\subsubsection{Hemocytes manipulation and stain: istepi}

1. Wash away the anticoagulant by centrifuging for 15 minutes at $780 \mathrm{~g}(3000 \mathrm{rpm})$.

2. Resuspend the hemocytes by adding $500 \mu$ of filtered sea water in a solution of $1 / 3$ Anticoagulant and 2/3 FSW to prevent the posterior coagulation.

3. Gently stir the suspension with a micropipette. Do not use a mechanical stirrer. istept

-Prepare slides with hemocytes to stains

1. 6 drops of $20 \mu \mathrm{l}$ of isolated hemocytes were left for $30 \mathrm{~min}$ to attach on SuperFrost or Poly-L Lysine microscopy slides, in a humid chamber.

2.The drop was then discarded by placing the slide vertically.

3. The slides with hemocytes are ready to use by stains.

\section{-Hematoxylin and eosin stain}

1. Use the slides with the previously attached hemocytes.

2. Fix for $15 \mathrm{~min}$ at $4{ }^{\circ} \mathrm{C}$ in $4 \%$ Paraformaldehyde ( In this case for the availability $4 \%$ formaldehyde with good quality)

3. Wash with PBS.

4. Stain using Meyer hematoxylin for 10 minutes.

5. Distillate water for 5 minutes.

6. Eosin 5 for minutes.

7. Ethanol $70 \%$ for 45 seconds.

8. Mounting using glycerin and sealed with a coverslip using nail polish.

-Giemsa stain to hemocytes

1. Use the slides with the previously attached hemocytes.

2. Fix for $30 \mathrm{~min}$ at $4{ }^{\circ} \mathrm{C}$ in ascidian fixative solution $(1 \mathrm{~g} \mathrm{NaCl}$ and $1 \mathrm{~g}$ sucrose in $1 \%$ glutaraldehyde in FSW).

3. Wash the slides with $1 \mathrm{X}$ PBS

4. Stain using $10 \%$ Giemsa stain by 5 minutes.

5. Mounting using glycerin and sealed with a coverslip using nail polish.

-Neutral red

1. After adhesion of hemocytes to slides, put $60 \mu \mathrm{l}$ of Neutral Red (Merck) solution $(8 \mathrm{mg} / \mathrm{L})$ in FSW.

2. Living hemocytes were directly observed.

Note:This dye specifically stains acid compartments (e.g., lysosomes or acid vacuolate contents) of living cells (Mazzi, 1977).

\section{-Sudan Black for lipids}

1. After adhesion of hemocytes to slides

2. Wash the slides with $1 \mathrm{X}$ PBS

3. Wash the slides with $70 \%$ ethanol for $30 \mathrm{sec}$

4. Stain with a saturated solution of Sudan Black (Sigma) in $70 \%$ ethanol for 15 min at $70^{\circ} \mathrm{C}$.

5. Wash with $70 \%$ ethanol and wash in distilled water.

6. Mounting using glycerin and sealed with a coverslip using nail polish.

Note: Black spots revealed the presence of lipids.

\subsection{Process 3B: RNA extraction}

6.4.1 For the Tri-Reagent protocol follows a previously described protocol (Sambrook \& Russell, 2001). 


\section{Materials:}

-PBS $1 \mathrm{x}$ cold.

-Trizol or TRI reagent.

-Chloroform.

-Free RNAse $\mathrm{H} 2 \mathrm{O}$

$-R N A$ precipitation solution:

$-1.2 \mathrm{M} \mathrm{NaCl}$

$-0.8 \mathrm{M}$ disodium citrate $15 \mathrm{H} 2 \mathrm{O}$.

- No adjustment $\mathrm{pH}$ is required.

-Plastic pistil for homogenization.

1. Wash the sample with sterile ice-cold PBS.

2. Homogenize tissue samples in TRIzol ( $1 \mathrm{ml}$ per 50-100 $\mathrm{mg}$ of tissue) with an appropriate homogenizer.

3. Wait 5 minutes at room temperature.

4. Centrifuge the homogenate at $12,000 \mathrm{rpm}$ for 10 minutes at $4{ }^{\circ} \mathrm{C}$ to remove the insoluble material (extracellular membranes, polysaccharides).

5. Transfer the clear supernatant to a fresh tube.

6. Add $200 \mathrm{ul}$ of chloroform per $\mathrm{ml}$ of TRIzol used.

7. Shake vigorously for 15 seconds and allow to stand for 5 minutes at $4{ }^{\circ} \mathrm{C}$.

8. Centrifuge the resulting mixture at $12,000 \mathrm{rpm}$ for 15 minutes at $4^{\circ} \mathrm{C}$.

9. Transfer the upper aqueous phase to a fresh tube.

10. Repeat the steps of organic separation (6-9 steps).

11.Precipitate the RNA: for each initial $\mathrm{ml}$ of TRIzol, add 250ul for isopropanol and $250 \mathrm{ul}$ of $R N A$ precipitation solution.

12. Mix and and wait for 10 minutes at $4^{\circ} \mathrm{C}$.

13. Centrifuge the resulting mixture at $12,000 \mathrm{rpm}$ for 10 minutes at $4^{\circ} \mathrm{C}$.

14. Briefly dry the RNA pellet for 5 minutes by air-drying.

15. Wash the pellet twice with $75 \%$ ethanol and centrifuge at $12,000 \mathrm{rpm}$ for 5 minutes at $4{ }^{\circ} \mathrm{C}$.

16. Remove any remaining ethanol, store the open tube on the bench for a few minutes to allow the ethanol evaporate. Do not allow pellet to dry completely.

17. Add $25 \mathrm{ul}$ of free RNAse $\mathrm{H} 2 \mathrm{O}$, storage at $-80^{\circ} \mathrm{C}$.

6.4.2 RNA extraction using LiCl for precipitation following Barlow et al., (1963) protocol Materials:

-Razer blades. 
-Tweezers

-Spatula

-Scissors

-All these tool need to be autoclaved in the oven during $200^{\circ} \mathrm{C}$ by 4 hours.

-Metal beads for plants $5 \mathrm{~mm}$.

-Eppendorf $2 \mathrm{ml}$

-Tissue lysser machine

-Chloroform

-Free RNAse H2O

-Liquid Nitrogen

-Extraction buffer:

$-0,2$ M Tris-Hcl pH 7,5

$-0,1 \mathrm{M} \mathrm{LiCl}$

$-5 \mathrm{mM}$ EDTA

$-1 / 10$ of the total volume of SDS $10 \%$

-Autoclave the final solution

\section{Tunicates samples}

-For fresh material maintain the tunicate one day before in filtered sea water.

-For colonial tunicates clean the glass slide and the colony with a soft paintbrush.

-For solitary tunicates remove the tunic and use muscle for the mantle avoiding the digestive structures.

Day 1

1. Put the tissues in the $2 \mathrm{ml}$ eppendorf and freeze intermediately in liquid nitrogen.

2. Put one bead metal bead in the eppendorf and shake the tube using a Tissues lysser machine during 40 seconds at a frequency of 30 revolution per second.

3. Add $0,5 \mathrm{ml}$ of extraction buffer.

4. Add $0,5 \mathrm{ml}$ of phenol:chloroform (1:1).

5. Dissolve the sample powder with vortex by 30 seconds.

6. Centrifuge the homogenate at $14000 \mathrm{rpm}$ for 5 minutes at $4^{\circ} \mathrm{C}$.

7. Transfer the upper aqueous phase to a fresh tube. Add the same volume $1 \mathrm{X}$ of $6 \mathrm{M} \mathrm{LiCl}$.

8. Storage the tubes in a recipient with ice and storage at $-20^{\circ} \mathrm{C}$ overnight.

Day 2

9. Centrifuge the sample at $14000 \mathrm{rpm}$ for 10 minutes at $4^{\circ} \mathrm{C}$.

10. Discard the supernatant.

11. Resuspend the precipitate in $1 \mathrm{ml}$ of $3 \mathrm{M} \mathrm{LiCl}$.

12. Shake in vortex by 30 seconds.

13. Centrifuge the sample at $14000 \mathrm{rpm}$ for 10 minutes at $4^{\circ} \mathrm{C}$.

14. Discard the supernatant. 
15. Resuspend the precipitate in $0,25 \mathrm{ml}$ of free RNAse $\mathrm{H} 2 \mathrm{O}$.

16. Centrifuge the homogenate at $14000 \mathrm{rpm}$ for 1 minutes at $4{ }^{\circ} \mathrm{C}$ to remove the insoluble material (extracellular membranes, polysaccharides).

17. Transfer the upper aqueous phase to a fresh tube. Add the same volume $0,1 \mathrm{X}$ of $3 \mathrm{M}$ Sodium acetate and $2 \mathrm{x}$ of ethanol $100 \%$.

18. Homogenate the tube manually.

19. Storage at $-80^{\circ} \mathrm{C}$ for 15 minutes.

20. Centrifuge the sample at $14000 \mathrm{rpm}$ for 15 minutes at $4^{\circ} \mathrm{C}$.

21. Discard the supernatant.

22. Add $1 \mathrm{ml}$ of ethanol $70 \%$, homogenate manually.

23. Centrifuge the sample at $14000 \mathrm{rpm}$ for 5 minutes at $4^{\circ} \mathrm{C}$.

24. Discard the supernatant manually.

25. Store the open tube on the bench for a few minutes to allow the ethanol evaporate.

26. Resuspend the precipitate in 20 ul of free RNAse $\mathrm{H} 2 \mathrm{O}$.

27. Incubate the homogenate at $55^{\circ} \mathrm{C}$ for 15 minutes to dilute the RNA precipitate, then storage at $80^{\circ} \mathrm{C}$. 